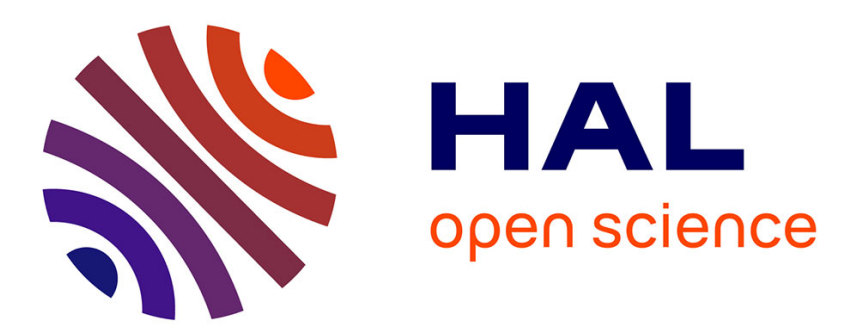

\title{
Genotypic parameters of wood density and fiber traits in triploid hybrid clones of Populus tomentosa at five clonal trials
}

Feng Wu, Pingdong Zhang, Jicheng Pei, Xiangyang Kang

\section{- To cite this version:}

Feng Wu, Pingdong Zhang, Jicheng Pei, Xiangyang Kang. Genotypic parameters of wood density and fiber traits in triploid hybrid clones of Populus tomentosa at five clonal trials. Annals of Forest Science, 2013, 70 (7), pp.751-759. 10.1007/s13595-013-0307-7 . hal-01201509

\author{
HAL Id: hal-01201509 \\ https://hal.science/hal-01201509
}

Submitted on 17 Sep 2015

HAL is a multi-disciplinary open access archive for the deposit and dissemination of scientific research documents, whether they are published or not. The documents may come from teaching and research institutions in France or abroad, or from public or private research centers.
L'archive ouverte pluridisciplinaire HAL, est destinée au dépôt et à la diffusion de documents scientifiques de niveau recherche, publiés ou non, émanant des établissements d'enseignement et de recherche français ou étrangers, des laboratoires publics ou privés. 


\title{
Genotypic parameters of wood density and fiber traits in triploid hybrid clones of Populus tomentosa at five clonal trials
}

\author{
Feng Wu • Pingdong Zhang • Jicheng Pei • \\ Xiangyang Kang
}

Received: 14 July 2012 / Accepted: 31 May 2013 /Published online: 20 June 2013

(C) INRA and Springer-Verlag France 2013

\begin{abstract}
- Context A clear understanding of the genetic control of wood properties is a prerequisite for breeding for higher wood quality in Populus tomentosa Carr. hybrid clones.

- Aims The experiments aimed at unraveling genetic and environmental effects on wood properties among triploid hybrid clones of $P$. tomentosa.

- Methods We used 5-year-old clonal trials established in Northern China to assess the heritability of wood density and fiber traits. Two hundred seventy trees from nine clones were sampled in five sites.

- Results Site had a very significant effect on all recorded traits. Despite this large site effect, a tight genetic control was detected and clonal repeatability varied between 0.53 and 0.95 . Significant genotype $\times$ environment interactions were
\end{abstract}

\section{Handling Editor: Christophe Plomion}

Contribution of the co-authors FW was responsible for collecting wood disks sample, wood density and fiber properties measurements, for generating the phenotypic data set, analyzing the results, and the writing of the paper. This work is a part of his $\mathrm{PhD}$ thesis. PDZ was responsible for planning and building the clonal trials and for collecting wood disks sample. He provides comments to statistical and genetic analysis. He co-writes the paper with FW.

JCP was responsible for planning the measurements of fiber properties and performing the LW fiber Tester at TUST.

$\mathrm{XYK}$ was responsible for planning and guiding this research. He provides comments to the text. He is supervisor of FW PhD.

F. Wu $\cdot$ P. Zhang $\cdot$ X. Kang $(\bowtie)$

National Engineering Laboratory for Tree Breeding, Key

Laboratory of Genetics and Breeding in Forest Trees and

Ornamental Plants, Ministry of Education, College of Biological

Sciences and Biotechnology, Beijing Forestry University, No.35,

Qinghua East Road, Haidian District, 100083 Beijing, People's

Republic of China

e-mail: Kangxy@bjfu.edu.cn

J. Pei

Papermaking Laboratory, Tianjin University of Science \&

Technology (TUST), No. 29 at 13th street TEDA, 300457

Tianjin, People's Republic of China detected for most of the traits. Moderate to tight correlation were evidenced among traits but they were not consistent with that in several cases that were site-dependent.

- Conclusions Our results revealed a tight genetic control over several wood properties and therefore breeding programs might be able to improve wood density, fiber length, and coarseness in these hybrids.

Keywords Triploid clones $\cdot$ Populus tomentosa $\cdot$ Wood density $\cdot$ Fiber traits $\cdot$ Clonal repeatability $\cdot$ Genotypic correlation

\section{Introduction}

Wood and fiber properties are very important for the properties of pulp and the subsequent production of paper. It has been shown that wood density is an indicator of pulp yield and has always had an impact on paper quality (Schimleck et al. 1999). Paper properties are highly correlated to fiber traits, such as fiber length, fiber width, and coarseness (Karlsson 2006; Mansfield and Weineisen 2007). However, wood density and fiber properties generally show a high heritability and respond well to genetic improvement (Zobel and van Buijtenen 1989). Furthermore, the wood properties stem from interplay between environment and genotype, which is an important interaction to consider in breeding programs to ensure precise estimates of breeding values. Moreover, some properties are highly correlated, making genetic correlations between wood traits integral to estimating the correlated response and in selection of specific breeding programs.

Triploid hybrids of Populus tomentosa are an important commercial species in northern China. These triploids are combined with both hybrid and polyploidy vigors. Hybrid vigors have been observed in poplar and are seen as a driving force in poplar breeding, while previous studies have demonstrated that triploid poplar hybrids have a high growth rate 
and longer fibers (Einspahr 1984; Zhu 2006). The wood is used in both the swan timber and pulp industries (Zhu 2006). Compared to $P$. tomentosa, the triploid hybrids have higher cellulose and holocellulose content and lower lignin content (Yang et al. 2006; Zhu 2006). Due to the aforementioned advantages, triploid hybrids of $P$. tomentos $a$ clones are widely planted in the Hebei, Henan, Shandong, and Shanxi provinces in order to obtain a high fiber yield from the crops.

In China, triploid breeding programs for P. tomentosa have mainly emphasized improvements in tree growth, trunk formation, disease resistance, and adaptability (Zhu 2006). Several studies have focused on the wood properties of $P$. tomentosa. Xing and Zhang (2000) reported variations in wood density among clones, radial direction, and vertical direction. Pu et al. (2002) examined variations in fiber morphology between clones and annual rings, while $\mathrm{Wu}$ et al. (2011) studied the genetic parameters of fiber traits. However, these studies were performed on a single site and lacked a description of the relationship between wood density and fiber traits, or failed to analyze correlations between different fiber traits. In addition, our previous work (Zhang et al. 2012) has analyzed the genetic variation of basic wood density (BWD) and fiber length (FL), and their relationship to growth rate. However, the systematic analyses for BWD and fiber properties are still necessary to guide the incorporation of wood with high quality traits into tree breeding programs for the pulp and paper industry.

The objectives of this study were to (1) describe BWD, FL, fiber width (FW), ratio of fiber length to width (FL/W), and fiber coarseness $(\mathrm{C})$ in triploid hybrids poplar from five clonal trials in northern China; (2) evaluate inheritance of these traits; (3) estimate genotype and environment interactions for these traits; and (4) examine the genotypic relationships between these traits.

\section{Material and method}

\subsection{Materials}

The materials used in this study came from five triploid hybrid poplar clonal trials in northern China, which were established from cuttings by Beijing Forestry University on agricultural soil with typical conditions of site fertility for $P$. tomentosa. Characteristics of the five clonal trials are presented in Table 1 . The planted cuttings were $20-25 \mathrm{~cm}$ in length and $1.5-2.0 \mathrm{~cm}$ in diameter. Clonal trials were established in a randomized block design with three blocks. The trials consisted of nine triploid hybrid clones on each site. The triploid hybrid clones were induced from a crossing between a $2 \mathrm{n}$ pollen producer of diploid $P$. tomentosa and a diploid hybrid P. tomentosa $\times$ Populus bolleana L. (Zhu et al. 1995) or a diploid hybrid Populus alba L. $\times$ Populus glandulosa Uyeki (Zhu, unpublished). Seven of them came from the first hybrid combination, while the $P$. tomentos $a \times P$. bolleana parents were produced in Beijing by $\mathrm{Xu}$ in 1958 . The $P$. alba $\times P$. glandulosa parents were introduced from Korea in 1984. No thinning was applied during the trial period until the time of sampling.

A total of 270 trees were sampled from the five sites in the spring of 2009 and 2010, so as to retain the consistency of the 5 -year-old sample. Trees were sampled randomly, six ramets (from the six different trees) per clone were chosen fully at random on each site.

\subsection{Measurements}

To assess wood properties, a 10 -cm-thick disk was taken from each tree at breast height $(1.3 \mathrm{~m})$ above ground level. For each disk, the BWD was determined, on a small rectangular pith-to-bark wood specimen with dimensions of $20 \mathrm{~mm}$ vertically $\times 20 \mathrm{~mm}$ radially, using the maximum moisture content method described by Smith (1954).

For intraring analysis of fiber properties, matchstick-sized wood specimens (each representing two annual ring pairs) were chipped away from the stem disks and then macerated in a boiling 1:1 $(\mathrm{v} / \mathrm{v})$ mixture of acetic acid and hydrogen peroxide. Thereafter, FL and FW were measured using the L\&W Fiber Tester (AB Lorentzen \& Wettre, Kista, Sweden) based on imaging analysis. During the fiber measurements, a highly diluted suspension flowed between the two glass plates, which are close to each other and thus limits the possibility of the fibers moving in one direction but allows them to move freely in the other two directions. As a result, the two-dimensional images permit the measurement of fiber

Table 1 Location, climatic conditions and description of five clonal trials

\begin{tabular}{|c|c|c|c|c|c|c|c|}
\hline Site & $\begin{array}{l}\text { Latitude } \\
{ }^{\circ} \mathrm{N}\end{array}$ & $\begin{array}{l}\text { Longitude } \\
{ }^{\circ} \mathrm{W}\end{array}$ & $\begin{array}{l}\text { Mean annual } \\
\mathrm{T}\left({ }^{\circ} \mathrm{C}\right)\end{array}$ & $\begin{array}{l}\text { Rainfall } \\
\text { mm/year }\end{array}$ & $\begin{array}{l}\text { Tree spacing } \\
\mathrm{m}\end{array}$ & Numbers of clones & Sample trees \\
\hline Yanzhou & $35^{\circ} 10^{\prime}$ & $116^{\circ} 49^{\prime}$ & 13.6 & 660 & $2 \times 3$ & 9 & 54 \\
\hline Gaotang & $36^{\circ} 51^{\prime}$ & $116^{\circ} 04^{\prime}$ & 13.1 & 556 & $2 \times 3$ & 9 & 54 \\
\hline Xiangfen & $35^{\circ} 50^{\prime}$ & $111^{\circ} 21^{\prime}$ & 11.5 & 550 & $2 \times 3$ & 9 & 54 \\
\hline Taiyuan & $37^{\circ} 52^{\prime}$ & $112^{\circ} 33^{\prime}$ & 10.5 & 431 & $2 \times 3$ & 9 & 54 \\
\hline Zhengzhou & $34^{\circ} 72^{\prime}$ & $113^{\circ} 97^{\prime}$ & 14.2 & 641 & $2 \times 3$ & 9 & 54 \\
\hline
\end{tabular}


length and deformations separately. According to the high speed of the L\&W Fiber Tester, about 5,000 fibers were measured on each sample within a few minutes. $\mathrm{C}$ was calculated based on dry mass of the sample and total length of fibers was measured by the L\&W Fiber Tester, and FL/W was calculated based on FL and FW measured.

\subsection{Statistical analysis}

Variance analysis was done using the GLM procedure in SAS Release 9.2 (SAS Institute, Cary, NC, USA). The following linear models were used for joint analyses (1) of the five sites together and for separate analyses (2) of individual sites:

$$
\begin{aligned}
& Y_{i j k}=\mu+S_{j}+C_{i}+C_{i} S_{j}+e_{i j k} \\
& Y_{i k}=\mu+C_{i}+e_{i k}
\end{aligned}
$$

where $Y_{i j k}$ is an observation on the $k$ th ramet from the $i$ th clone in the $j$ th site, $Y_{i k}$ an observation on the $k$ th ramet from the $i$ th clone, $\mu$ is the overall mean, $S_{j}$ is the random effect due to the $j$ th site, $C_{i}$ is the fixed effect due to the $i$ th clone, $C_{i} S_{j}$ is the random effect of interaction between the $i$ th clone and $j$ th site, and $e_{i j k}$ and $e_{i k}$ are the random residuals. The models assume that the random effects are normally distributed with the expectation equal to zero and corresponding $\widehat{\sigma}_{c}^{2}, \widehat{\sigma}_{c s}^{2}$ and $\widehat{\sigma}_{e}^{2}$.

\subsection{Estimates of genetic parameters}

Variance components were derived separately from the model (2) for each site. Genetic parameters and their standard errors were estimated using variances and covariances obtained from the SAS VARCOMP procedure by residual maximum likelihood estimation method. The genotypic variance component, which corresponds to broad-sense heritability, was expressed in percents of total phenotypic variation of all random effects using the formula:

$$
\widehat{\sigma}_{G}^{2}=\frac{\widehat{\sigma}_{c}^{2} 100}{\widehat{\sigma}_{c}^{2}+\widehat{\sigma}_{\mathrm{e}}^{2}}
$$

where $\widehat{\sigma}_{c}^{2}$ is the genotypic (clonal) variance component and $\widehat{\sigma}_{e}^{2}$ is the residual variance.

The genotypic coefficient of variation was calculated using the following formula:

$\mathrm{CV}_{\mathrm{G}}=\frac{\sqrt{\widehat{\sigma}_{c}^{2}} 100}{\bar{X}}$

where $\bar{X}$ is the phenotypic mean. Similarly, the environmental coefficient of variation was calculated from the residual variance. The coefficient of phenotypic variation was obtained from the phenotypic variance component which was estimated as $\widehat{\sigma}_{p}^{2}=\widehat{\sigma}_{c}^{2}+\widehat{\sigma}_{e}^{2}$.

The repeatability of clonal means $\left(R_{c}^{2}\right)$ was estimated as:

$R_{c}^{2}=\frac{\widehat{\sigma}_{c}^{2}}{\widehat{\sigma}_{c}^{2}+\widehat{\sigma}_{\mathrm{e}}^{2} / k}$

where $k$ is the harmonic mean number of sampled trees per clone within a site. The standard errors for repeatability estimates were calculated based on the formula by Becker (1984):

S.E. $\left(R_{c}^{2}\right)=\sqrt{\frac{2(n-1)\left(1-R_{c}^{2}\right)^{2}\left[1+(k-1) R_{c}^{2}\right]^{2}}{k^{2}(n-N)(N-1)}}$

where $N$ is the number of clones tested and $n$ is the total number of individual values.

Genotypic correlation coefficients $\left(r_{G}\right)$ between traits at each site were estimated as (Becker 1984):

$r_{G}=\frac{\widehat{\sigma}_{\mathrm{c}(\mathrm{xy})}}{\sqrt{\widehat{\sigma}_{\mathrm{c}(\mathrm{x})}^{2}} \times \sqrt{\widehat{\sigma}_{\mathrm{c}(\mathrm{y})}^{2}}}$

where $\widehat{\sigma}_{\mathrm{c}(\mathrm{xy})}$ is the clone covariance component, $\widehat{\sigma}_{\mathrm{c}(\mathrm{x})}^{2}$ is the clone variance component for the trait $x$, and $\widehat{\sigma}_{\mathrm{c}(y)}^{2}$ is the clone variance component for the trait $y$. To calculate genotypic correlation coefficients, the data were standardized to mean $=0$ and $\sigma=1$. Because of sampling errors and mathematical approximation, some genotypic correlations exceeded \pm 1 . In these cases, they were assumed to be equal to \pm 1 considering the asymptotic nature of distribution of correlation coefficients. The covariance component was estimated using the following equation:

$\widehat{\sigma}_{\mathrm{c}(\mathrm{xy})}=\frac{\widehat{\sigma}_{\mathrm{c}(\mathrm{x}+\mathrm{y})}^{2}-\widehat{\sigma}_{\mathrm{c}(\mathrm{x})}^{2}-\widehat{\sigma}_{\mathrm{c}(\mathrm{y})}^{2}}{2}$

where $\widehat{\sigma}_{\mathrm{c}(x+y)}^{2}$ is the variance component for the sum of trait $x$ and $y$. The standard errors of genotypic correlations were estimated using the following equation (Falconer 1981):

$\sigma=\frac{1-r_{G}^{2}}{\sqrt{2}} \sqrt{\frac{\widehat{\sigma}_{\left(R_{x}^{2}\right)} \widehat{\sigma}_{\left(R_{y}^{2}\right)}}{R_{x}^{2} R_{y}^{2}}}$

where $R_{x}^{2}$ is the repeatability estimate of the character $x, x, R_{y}^{2}$ is the repeatability estimate of the character $y, \widehat{\sigma}_{\left(R_{x}^{2}\right)}$ is the standard error of $R_{x}^{2}$, and $\widehat{\sigma}\left(R_{y}^{2}\right)$ is the standard error of $R_{y}^{2}$. Moreover, the significance of the genotypic correlations was tested with the $t$ test. 
The magnitudes of genotype by environment interactions were estimated by analyzing combined sites under the general linear mixed model given in Eq. (1). According to Falconer (1981), the expression of a trait in two different environments can be viewed as two distinct characters, the computation of a genetic correlation between them were able to evaluate the contribution of each pair of treatments to the total clone $\times$ environment interaction. These type B genotypic correlations (Burdon 1977) were estimated based on measurements of sample ramets from the same clones planted on different sites using the following formula:

$r_{B(X, Y)}=\frac{r_{\mathrm{p}}(x 1, y 2)}{R_{C(x 1)} R_{C(y 2)}}$

where $r_{p(x 1, y 2)}$ is the phenotypic correlation coefficient between the clone means estimated between $x$ measured in site 1 and y measured in site 2 and $R_{C(x 1)}$ and $R_{C(y 2)}$ are the square roots of their clonal mean repeatability, estimated for $x$ and $y$ at sites 1 and 2, respectively.

\section{Results}

\subsection{Mean values and site effects}

The means and one standard error of the mean of all the studied traits in each of the five clonal trials of triploid poplar are presented in Table 2. Trees at the Zhengzhou site had the lowest BWD. The highest BWD was observed at the Gaotang site, with the difference between the lowest and highest average BWD amounting to $8.1 \%$ (Table 2). The fiber of the triploid poplar was longest at the Gaotang site, whereas the triploid poplar had a minimum FW so that the FL/W of the triploid poplar was largest at it. Nevertheless, the fiber of the triploid poplar was shortest at the Yanzhou site and narrowest at the Zhengzhou site. The $\mathrm{C}$ of trees at the Zhengzhou site was $12.1 \%$ higher than the $\mathrm{C}$ of those at the Xiangfen site. The joint analysis of all five trials (model 1) showed significant site effects for BWD and fiber traits (Table 3).

\subsection{Clonal variation and repeatability}

The joint analysis (model 1) indicated significant $(P<0.001)$ clonal effects for BWD, FL, FW, FL/W, and C (Table 3). The analysis of variance, repeatability and coefficients of genotypic, environmental, and phenotypic variation at each individual site are presented in Table 4. Significant differences $(P<0.01)$ were found among clones for all traits at five sites (model 2), except the FL/W at the Xiangfen, Taiyuan, and Zhengzhou sites, for which the level of significance of clonal effects was not high $(0.01<P<0.05)$. However, the highest significance of clonal effects (model 2) was obtained from FW at the Yanzhou site, where the clonal effects were relatively higher than other sites (Table 4). Genotypic variations of all traits were rather low, with the coefficient of genotypic variation $\left(\mathrm{CV}_{\mathrm{G}}\right)$ at individual sites being of the same magnitude (1.4-6.4\%). In general, the $\mathrm{CV}_{\mathrm{G}}$ of fiber traits was lower than that of BWD, except for C (Table 4). However, clonal repeatability of BWD was lower than that of most fiber traits at each individual site, excluding BWD at the Xiangfen site. Repeatability of FL/W at Yanzhou site was up to 0.93 , which was rather high compared to the FL/W of other sites. Repeatability of BWD and fiber traits at the Zhengzhou site was relatively lower than at almost all other sites (Table 4).

\subsection{Genotype by environment interaction}

The clone $\times$ site interaction was significant for BWD and fiber traits (Table 3). However, the level of significance for FL and FW were not high $(0.001<P<0.01)$, and that for $\mathrm{FL} / \mathrm{W}$ was rather low $(0.01<P<0.05)$. Type $\mathrm{B}$ genetic correlations were used to measure the importance of genotype by environment interactions for BWD and to measure fiber properties of the triploid poplar from combined sites analysis. Most of intersite (B type) genotypic correlations between the same trait at pairs of sites were moderate or strong and significant, except that for FL/FW at Yanzhou-Taiyuan and Xiangfen-Taiyuan sites (Table 5). For BWD and FL, correlations were lower when the Yanzhou and Taiyuan site was involved, respectively.

Table 2 Means and one standard error of the mean (SE) of wood density and fiber traits of triploid poplars at the five clonal trials

\begin{tabular}{|c|c|c|c|c|c|c|c|c|c|c|}
\hline \multirow[t]{2}{*}{ Trait(site) } & \multicolumn{2}{|c|}{ Gaotang } & \multicolumn{2}{|c|}{ Yanzhou } & \multicolumn{2}{|c|}{ Xiangfen } & \multicolumn{2}{|c|}{ Taiyuan } & \multicolumn{2}{|c|}{ Zhengzhou } \\
\hline & Mean & SE & Mean & SE & Mean & SE & Mean & SE & Mean & SE \\
\hline BWD $\left(\mathrm{kg} / \mathrm{m}^{3}\right)$ & 346.8 & (8.7) & 324.3 & $(9.8)$ & 326.3 & $(7.8)$ & 337.0 & (7.6) & 320.9 & (9.6) \\
\hline FL (mm) & 0.82 & $(0.04)$ & 0.77 & $(0.04)$ & 0.80 & $(0.04)$ & 0.78 & $(0.04)$ & 0.81 & $(0.04)$ \\
\hline $\mathrm{FW}(\mu \mathrm{m})$ & 24.2 & $(0.9)$ & 24.7 & $(0.9)$ & 24.2 & $(0.9)$ & 24.6 & $(0.9)$ & 25.4 & $(0.8)$ \\
\hline $\mathrm{FL} / \mathrm{W}$ & 33.9 & (1.5) & 31.3 & (1.4) & 33.1 & $(1.2)$ & 31.7 & (1.1) & 32.1 & (1.5) \\
\hline $\mathrm{C}(\mu \mathrm{g} / \mathrm{m})$ & 102.2 & (7.4) & 105.8 & (8.9) & 100.2 & (8.3) & 103.0 & (8.1) & 112.3 & (8.6) \\
\hline
\end{tabular}

$B W D$ basic wood density, $F L$ fiber length, $F W$ fiber width, $F L / W$ fiber length/width, $C$ Coarseness 
Table 3 Significance levels ( $p$ values) of factors, which results from the joint mixed linear model analysis of variance of wood density and fiber properties of the triploid poplar clones at five sites combined

\begin{tabular}{|c|c|c|c|c|c|}
\hline \multirow[t]{2}{*}{ Factors } & \multicolumn{5}{|l|}{ Traits } \\
\hline & BWD & FL & $\mathrm{FW}$ & $\mathrm{FL} / \mathrm{W}$ & $\mathrm{C}$ \\
\hline Site & $<0.001^{* * *}$ & $<0.001^{* * *}$ & $<0.001^{* * *}$ & $<0.001^{* * *}$ & $<0.001^{* * *}$ \\
\hline Clone & $<0.001^{* * *}$ & $<0.001^{* * *}$ & $<0.001^{* * *}$ & $<0.001^{* * *}$ & $<0.001^{* * *}$ \\
\hline Clone $\times$ site & $<0.001^{* * *}$ & $0.002^{* *}$ & $0.008^{* *}$ & $0.014^{*}$ & $<0.001^{* * * *}$ \\
\hline
\end{tabular}

\subsection{Genotypic correlations between traits}

Genotypic correlations between traits at individual sites are presented in Table 6. Moderate to strong (0.41-1.00) and significant positive genotypic correlations between BWD and fiber traits were found at specific locales, except when the BWD was strong or weakly correlated with the FL/W at the Yanzhou, Taiyuan, and Zhengzhou sites. However, correlations between BWD and fiber traits at the Yanzhou site were much lower than those at the Gaotang site (Table 6). FL had moderate to strong correlations with the other three fiber traits at individual sites. The relationships between $\mathrm{FW}$ and $\mathrm{C}$ were very strong $(0.91-1.00)$ at all sites. Correlations between $\mathrm{FL} / \mathrm{W}$ and $\mathrm{FW}$ or $\mathrm{C}$ were positive and moderately significant at the Taiyuan site, but these correlations were positively weak or negatively weak to moderate at other sites.

\section{Discussion}

4.1 Mean values and site effects

According to the five clonal trails in this study, the mean BWD values of triploid poplar hybrids, which varied from 320.9 to
Table 4 Results from the model (2) analysis of wood density and fiber properties of triploid poplar clones at five sites: the effect of clones on the value of the $F$ test, repeatability of clonal means, and coefficients of genotypic, environmental, and phenotypic variation
${ }^{* *} P<0.01 ;{ }^{*} 0.01<P<0.05$, level of significance of the clonal effect

\begin{tabular}{|c|c|c|c|c|c|}
\hline & Clone $F$ value & $R^{2} \pm \mathrm{SE}$ & $\mathrm{CV}_{\mathrm{G}}(\%)$ & $\mathrm{CV}_{\mathrm{e}}(\%)$ & $\mathrm{CV}_{\mathrm{p}}(\%)$ \\
\hline \multicolumn{6}{|l|}{ Gaotang } \\
\hline BWD & $3.57^{* *}$ & $0.72 \pm 0.12$ & 4.0 & 4.7 & 6.1 \\
\hline FL & $7.73^{* *}$ & $0.87 \pm 0.06$ & 3.5 & 3.3 & 4.8 \\
\hline FW & $9.38^{* *}$ & $0.89 \pm 0.05$ & 2.6 & 2.2 & 3.4 \\
\hline $\mathrm{FL} / \mathrm{W}$ & $3.57^{* *}$ & $0.72 \pm 0.12$ & 2.0 & 3.0 & 3.6 \\
\hline $\mathrm{C}$ & $17.73^{* *}$ & $0.94 \pm 0.03$ & 6.3 & 3.8 & 7.4 \\
\hline \multicolumn{6}{|c|}{ Yanzhou } \\
\hline BWD & $2.63^{* *}$ & $0.62 \pm 0.14$ & 4.3 & 6.2 & 7.6 \\
\hline FL & $11.04^{* *}$ & $0.91 \pm 0.05$ & 4.1 & 3.2 & 5.2 \\
\hline FW & $18.44^{* *}$ & $0.95 \pm 0.03$ & 3.1 & 1.8 & 3.6 \\
\hline $\mathrm{FL} / \mathrm{W}$ & $13.44^{* *}$ & $0.93 \pm 0.04$ & 3.6 & 2.5 & 4.4 \\
\hline $\mathrm{C}$ & $7.27^{* *}$ & $0.86 \pm 0.07$ & 6.3 & 6.1 & 8.8 \\
\hline \multicolumn{6}{|c|}{ Xiangfen } \\
\hline BWD & $9.83^{* *}$ & $0.90 \pm 0.05$ & 4.3 & 3.6 & 5.6 \\
\hline FL & $4.46^{* *}$ & $0.78 \pm 0.10$ & 2.9 & 3.8 & 4.8 \\
\hline FW & $8.02^{* *}$ & $0.88 \pm 0.06$ & 2.8 & 2.6 & 3.8 \\
\hline $\mathrm{FL} / \mathrm{W}$ & $2.14^{*}$ & $0.53 \pm 0.15$ & 1.4 & 3.3 & 3.6 \\
\hline $\mathrm{C}$ & $6.61^{* *}$ & $0.85 \pm 0.07$ & 5.8 & 5.9 & 8.3 \\
\hline \multicolumn{6}{|l|}{ Taiyuan } \\
\hline BWD & $3.44^{* *}$ & $0.71 \pm 0.12$ & 4.5 & 7.0 & 8.4 \\
\hline FL & $5.20^{* *}$ & $0.81 \pm 0.09$ & 3.2 & 3.7 & 4.9 \\
\hline FW & $4.25^{* *}$ & $0.76 \pm 0.10$ & 2.1 & 2.8 & 3.4 \\
\hline $\mathrm{FL} / \mathrm{W}$ & $2.49^{*}$ & $0.60 \pm 0.15$ & 1.5 & 3.0 & 3.4 \\
\hline $\mathrm{C}$ & $10.38^{* *}$ & $0.90 \pm 0.05$ & 6.4 & 5.0 & 8.1 \\
\hline \multicolumn{6}{|c|}{ Zhengzhou } \\
\hline BWD & $3.20^{* *}$ & $0.69 \pm 0.11$ & 3.3 & 5.3 & 6.2 \\
\hline FL & $3.54^{* *}$ & $0.72 \pm 0.11$ & 2.5 & 3.8 & 4.6 \\
\hline FW & $4.53^{* *}$ & $0.78 \pm 0.09$ & 2.0 & 2.6 & 3.2 \\
\hline $\mathrm{FL} / \mathrm{W}$ & $2.30^{*}$ & $0.57 \pm 0.14$ & 1.9 & 4.0 & 4.5 \\
\hline $\mathrm{C}$ & $5.12^{* *}$ & $0.80 \pm 0.08$ & 4.8 & 5.7 & 7.5 \\
\hline
\end{tabular}


$346.8 \mathrm{~kg} / \mathrm{m}^{3}$, were similar to those reported previously for 9year-old clones of Populus euramericana (Beaudoin et al. 1992) and for 3-year-old clones of Populus deltoides (Olson et al. 1985). However, the present BWD values for triploid poplar hybrids are somewhat lower than those reported for 9year-old clones of the triploid $P$. tomentosa (Xing and Zhang 2000), 3-year-old poplar hybrids clones of $P$. deltoides (Zhang et al. 2003), and for 8-year-old clones of P. tomentosa (Song et al. 2000). These differences might be due to the methods of estimation of wood density, species variation within poplars, differences in environmental conditions, and differences in the cambial age of samples. Moreover, the polyploidy of triploid poplar hybrids might not be disregarded. Previous studies have reported that the triploid poplar hybrids have larger cells and a lower lignin content than those used for diploid poplar hybrids (Einspahr 1984; Zhu 2006). Conversely, wood density is influenced by both anatomical structure and chemical composition (Klasnja et al. 2003).

The mean FL measured in this study were near to those mentioned by Geyer et al. (2000) for 4-year-old hybrid poplar clones and Yu et al. (2001) for 13-year-old hybrid aspen clones; however, clearly shorter than those reported by $\mathrm{Pu}$ et al. (2002) for 9-year-old triploid poplar hybrids grown in the Hebei province of Northern China. Mean values ranged from 24.2 to $25.4 \mu \mathrm{m}$ for $\mathrm{FW}$ and 31.3 to 33.9 for FL/W, which were similar or slightly lower than those earlier reported by Fang et al. (2003) based on seven poplar hybrid clones and Pu et al. (2002). Since the fiber growth of triploid poplar hybrids is in the form of length extension rather than thickening of the fiber wall (Yang et al. 2006), it indicates that the FL/W of triploid poplar hybrids in this study might increase over a 5 -year period. In this study, the $\mathrm{C}$ values measured for triploid poplars were based on five sites ranging from 100.2 to $112.3 \mu \mathrm{g} / \mathrm{m}$, which were similar to poplar hybrid clones (Yu et al. 2001) and Populus tremuloides Michx. (Mansfield and Weineisen 2007), and were much higher than those of Aspen clones (Karlsson 2006).

In field-based experiments, it has been shown that many factors may impact wood and fiber properties including physiological age, genotype, method of culture, and heterogeneous field conditions (Pitre et al. 2007). In this study, the five clonal trials were carried out under controlled conditions with the only exceptions being in the aforementioned the field conditions. Significant site effects were observed for BWD and fiber traits (Table 3). Results indicated that edaphic and regional climatic conditions have significant wood property effects. These significant site effects on the wood density of poplar hybrids have been previously described and reported (Song et al. 2000; Zhang et al. 2003; Pliura et al. 2007). For fiber properties, some studies have shown that FL was more strongly influenced by genotype than by environment conditions (DeBell et al. 2002; Yu et al. 2001). Yu et al. (2001) reported a lack of interaction between fiber properties and test sites, while Pitre et al. (2007) reported that there was a short-term response on the fiber properties adapting to a shift in nitrogen availability, and Mansfield and Weineisen (2007) found that geographic location imparts influences on fiber coarseness traits of $P$. tremuloides Michx. Wood properties and composition are modulated by the developmental state as well as environmental conditions because the environmental conditions have various effects on fiber development and properties (Pitre et al. 2007). The significant site effects on fiber properties observed in this study may be attributed to differences in the developmental fiber stage or maturation caused by the diversity of environmental conditions of the five clonal trials.

\subsection{Clonal variation and repeatability}

Clonal effects in the joint analysis (model 1) for BWD and fiber traits were significant $(0.01<P<0.05)$. This finding was supported by Zobeland and van Buijtenen (1989) that wood and fiber properties were generally under strong genetic control. Previous studies (Yu et al. 2001; Zhang et al. 2003; Pliura et al. 2007) also reported a significant clonal effect in the wood density of poplars or their hybrids, as well as for fiber properties (Yu et al. 2001; DeBell et al. 2002; Fang and Yang 2003). Clonal effects on BWD and fiber traits varied

Table 5 Type B genetic correlations between sites for wood density and fiber properties of the triploid poplar clones

\begin{tabular}{|c|c|c|c|c|c|c|c|c|c|c|}
\hline \multirow[t]{2}{*}{ Trait } & \multicolumn{10}{|c|}{ Genotypic correlations between pairs of sites } \\
\hline & GT-YZ & $\mathrm{GT}-\mathrm{XF}$ & GT-TY & GT-ZZ & $\mathrm{YZ}-\mathrm{XF}$ & YZ-TY & YZ-ZZ & $\mathrm{XF}-\mathrm{TY}$ & $\mathrm{XF}-\mathrm{ZZ}$ & TY-ZZ \\
\hline BWD & $0.64^{* *}$ & $0.71^{* *}$ & $0.63^{* *}$ & $0.64^{* *}$ & $0.45^{* *}$ & $0.53^{* *}$ & $0.46^{* *}$ & $1.11^{* *}$ & $0.91^{* *}$ & $1.01^{* *}$ \\
\hline FL & $0.90^{* *}$ & $0.98^{* *}$ & $0.56^{* *}$ & $0.79^{* *}$ & $0.90^{* *}$ & $0.43^{*}$ & $0.60^{* *}$ & $0.62^{* *}$ & $1.15^{* *}$ & $0.73^{* *}$ \\
\hline FW & $0.95^{* *}$ & $0.87^{* *}$ & $1.11^{* *}$ & $0.93^{* *}$ & $0.59^{* *}$ & $0.99^{* *}$ & $0.85^{* *}$ & $1.09^{* *}$ & $0.78^{* *}$ & $0.97^{* *}$ \\
\hline $\mathrm{FL} / \mathrm{FW}$ & $0.65^{* *}$ & $1.13^{* *}$ & $1.11^{* *}$ & $0.64^{* *}$ & $0.68^{* *}$ & -0.01 & $1.01^{* *}$ & -0.23 & $0.74^{* *}$ & $0.86^{* *}$ \\
\hline $\mathrm{C}$ & $0.70^{* *}$ & $0.57^{* *}$ & $0.79^{* *}$ & $0.66^{* *}$ & $0.60^{* *}$ & $0.95^{* *}$ & $0.63^{* *}$ & $0.96^{* *}$ & $1.09^{* *}$ & $0.93^{* *}$ \\
\hline
\end{tabular}

GT Gaotang, YZ Yanzhou, XF Xiangfen, TY Taiyuan, ZZ Zhengzhou

${ }^{* *} P<0.01 ;{ }^{*} 0.01<P<0.05$, Level of significance of the correlations 
between sites (Table 2). This indicates the presence of interactions, which were probably caused by differences in climatic or edaphic conditions between the test sites.

Genetic variance standardized to the trait mean $\left(\mathrm{CV}_{\mathrm{G}}\right)$ is a more appropriate parameter than heritability for evaluating how traits will respond to selection. The values of $\mathrm{CV}_{\mathrm{G}}$ for $\mathrm{BWD}$ range from 3.3 to $4.6 \%$ (Table 4 ), which is consistent with Pliura et al. (2007), who reported $4.0-6.8 \% \mathrm{CV}_{\mathrm{G}}$ for the wood density of hybrid poplar clones. The $\mathrm{CV}_{\mathrm{G}}$ values of fiber traits in this study were consistent from site to site and were of the same magnitude as the $\mathrm{CV}_{\mathrm{G}}$ values for BWD (Table 4). In a study of an 11-year-old Betula pendula clone (Zhang et al. 2003), the $\mathrm{CV}_{\mathrm{G}}$ values of the wood and fiber properties were also quite low, ranging from 3.5 to $6.2 \%$. These indicate that there is an equivalent genetic potential for the improvement of $\mathrm{BWD}$ as for FL, FW, FL/W, and C. In addition, the $\mathrm{CV}_{\mathrm{G}}$ values of fiber traits in this study were lower than those of BWD, except for coarseness. However, the conclusions made by Cornelius (1994) based on reviewing a multitude of research papers on heritability and genetic variation in forest tress, suggests that the $\mathrm{CV}_{\mathrm{G}}$ of wood density tends to have a lower values than any of the other quality traits studied.

Repeatability estimates of triploid poplars in this study were medium to high (Table 4), which was consistent with those presented in the literature on poplar/poplar hybrids. Repeatability for BWD was estimated to be 0.92 in hybrid poplars (Zhang et al. 2003), ranging from 0.82 to 0.91 in $P$. tomentosa Carr. (Song et al. 2000). Yu et al. (2001) reported repeatability of FL and C across two sites at 0.65 and 0.56 , respectively. The analyses of clonal mean repeatability suggested that high genetic responses could be expected for BWD and fiber properties, following clonal selection of triploid poplars for industrial planting.

\subsection{Clone $\times$ site interactions}

Since triploid poplar breeding programs deal with developing clones suitable for different environments, genotype $\times$ site interactions may have a significant impact on the precision of breeding values estimates, thus reducing genetic gain. Due to incongruity between test locations and deployment zones, $\mathrm{G} \times \mathrm{E}$ interaction, if improperly accounted for, could result in a bias of estimates and thus in a decrease in genetic gain. The clone $\times$ site interaction was significant for BWD (Table 3). This finding was consistent with previous reports that significant clone $\times$ site interactions for wood density were observed in poplar hybrids (Zhang et al. 2003). Clone $\times$ site interactions effects for fiber traits were relative smaller than that for BWD, as levels of significance were not high for FL, FW, and FL/W (Table 3). Similar conclusions have been drawn for FL and $\mathrm{C}$ in hybrid aspens (Yu et al. 2001).

Type B genetic correlation is a measure of the importance of environment interactions on genotype, which provides a more precise detection of genotype $\times$ environment interactions (Burdon 1977). The absence of significant positive type B genotypic correlations between genotypic values at YanzhouTaiyuan and Xiangfen-Taiyuan sites for FL/FW (Table 5) indicated that true $\mathrm{G} \times \mathrm{E}$ interaction was present and that difference between these sites might be contributed the clone $\times$ site interaction. However, the type $\mathrm{B}$ genotypic correlations between sites for BWD, FL, FW, C, and in most case of FL/W were positive and strong (Table 5), which indicated that the wood properties of clones were rather stable across sites. Results of present study agree with conclusion by Zobel and Jett (1995) that performance of genotypes across environments for wood properties was rather stable.

\subsection{Genotypic correlations between traits}

The reports from previous studies on the relationship between wood density and fiber traits are often varied. For maritime pines, an insignificant genetic correlation has been obtained between wood density and FL (Pot et al. 2002), while FL was not correlated with wood density in poplars (Zhang et al. 2003).

Table 6 Genotypic correlation between traits of triploid poplar clones at individual sites

\begin{tabular}{|c|c|c|c|c|}
\hline Trait & FL & FW & $\mathrm{FL} / \mathrm{W}$ & $\mathrm{C}$ \\
\hline \multicolumn{5}{|l|}{ Gaotang } \\
\hline BWD & $0.98^{*}$ & $0.75^{*}$ & $0.57^{*}$ & $0.79^{*}$ \\
\hline FL & & $0.84^{*}$ & $0.66^{*}$ & $0.68^{*}$ \\
\hline FW & & & 0.14 & $0.91^{*}$ \\
\hline $\mathrm{FL} / \mathrm{W}$ & & & & -0.01 \\
\hline \multicolumn{5}{|c|}{ Yanzhou } \\
\hline BWD & $0.61^{*}$ & $0.59^{*}$ & 0.10 & $0.41^{*}$ \\
\hline FL & & $0.54^{*}$ & $0.67^{*}$ & $0.81^{*}$ \\
\hline FW & & & $-0.27^{*}$ & $0.93^{*}$ \\
\hline $\mathrm{FL} / \mathrm{W}$ & & & & 0.09 \\
\hline \multicolumn{5}{|c|}{ Xiangfen } \\
\hline BWD & $0.88^{*}$ & $0.52^{*}$ & $0.69^{*}$ & $0.68^{*}$ \\
\hline FL & & $0.88^{*}$ & $0.33^{*}$ & $0.67^{*}$ \\
\hline FW & & & -0.19 & $0.94^{*}$ \\
\hline $\mathrm{FL} / \mathrm{W}$ & & & & $-0.46^{*}$ \\
\hline \multicolumn{5}{|l|}{ Taiyuan } \\
\hline BWD & $0.63^{*}$ & $1.00^{*}$ & 0.04 & $1.00^{*}$ \\
\hline FL & & $0.92^{*}$ & $0.83^{*}$ & $0.91^{*}$ \\
\hline FW & & & $0.54^{*}$ & $1.00^{*}$ \\
\hline $\mathrm{FL} / \mathrm{W}$ & & & & $0.53^{*}$ \\
\hline \multicolumn{5}{|c|}{ Zhengzhou } \\
\hline BWD & $0.41^{*}$ & $0.60^{*}$ & 0.13 & $0.80^{*}$ \\
\hline FL & & $0.67^{*}$ & $0.63^{*}$ & $0.63^{*}$ \\
\hline FW & & & -0.18 & $0.94^{*}$ \\
\hline FL/W & & & & -0.15 \\
\hline
\end{tabular}

${ }^{*} 0.01<P<0.05$, level of significance of the genotypic correlations 
Luostarinen (2011) reported that in the Siberian larch (Larix sibirica Ledeb.), wood density was negative correlated with FW in $1-5$ years. Only after $15-20$ years did this correlation become positive. For $\mathrm{C}$, a negligible genetic correlation to density was obtained in the radiata pine (Nyakuengama et al. 1999). However, Pot et al. (2002) observed a strong relationship between wood density and $\mathrm{C}$ in maritime pines. In this study, BWD has shown significant positive correlations with fiber traits, except for no or weak correlations with FL/W in some sites. This indicated that the selection for BWD might be influenced by the fiber traits. Since BWD had high and positive genetic correlations with FL and $\mathrm{C}$, which are two traits very important to pulp and paper, these favorable correlations indicated that selection for BWD could increase FL and $\mathrm{C}$ in a triploid poplar selection program.

For fiber traits studied in our present research, the FL was significant and positively correlated with the other three traits, while the relationship between FL/W and FW or C varied in different clonal trials. These implied that FL could be a good predictor of fiber traits. However, the only significant relationship between the different fiber properties was obtained between FW and $\mathrm{C}$ in B. pendula (Stener and Hendenberg 2003). Nevertheless, a report (Via et al. 2004) based on a review of a multitude of research papers suggested that FL and $\mathrm{C}$ showed a weak genetic correlation in the radiata pine, but a very strong correlation in the maritime pine. The correlations between $\mathrm{FW}$ and $\mathrm{C}$ were quite high $\left(r_{G}\right.$ range from 0.91 to 1.00 ). Because $C$ is measured on a weight per unit length of fiber basis, these significant correlations have been expected.

Acknowledgments The author would like to thank Fangdong Zhang and Yatong Xie from Tianjin University of Science and Technology for their assistance with fiber properties measurements.

Funding This study was supported by the Forestry Public Benefit Research Foundation (20100400900-3).

\section{References}

Beaudoin M, Hernandez RE, Koubaa A, Poliquin J (1992) Interclonal, intraclonal and within-tree variation in wood density of poplar hybrid clones. Wood Fiber Sci 24:147-153

Becker WA (1984) Manual of quantitative genetics. Academic, Pullman, Washington, DC

Burdon RD (1977) Genetic correlation as a concept for studying genotype $\times$ environment interaction in forest tree breeding. Silvae Genet 26:168-175

Cornelius J (1994) Heritabilities and additive genetic coefficients of variation in forest trees. Can J For Res 24:372-379

DeBell DS, Singleton R, Harrington C, Gartner BL (2002) Wood density and fiber length in young Populus stems: relation to clone, age growth rate, and pruning. Wood Fiber Sci 34:529-539
Einspahr DW (1984) Production and utilization of triploid hybrid aspen. Iowa State J Res 58:401-409

Falconer DS (1981) Introduction to quantitative genetics, 2nd edn. Longman, London

Fang SZ, Yang WZ (2003) Interclonal and within-tree variation in wood properties of poplar clones. J For Res 14:263-268

Geyer WAG, Dewyke J, Walawender WP (2000) Biomass and gasification properties of young Populus clones. Wood Fiber Sci $32: 375-384$

Karlsson H (2006) Fibre guide. Fibre analysis and process applications in the pulp and paper industry. Lorentzen \& Wettre, Sweden

Klasnja B, Kopitovic S, Orlovic S (2003) Variability of some wood properties of eastern cottonwood (Populus deltoides Bartr.) clones. Wood Sci Technol 37:331-337

Luostarinen K (2011) Variation in fibre properties of cultivated Siberian larch (Larix sibirica Ledeb.) in relation to radial and axial locations in the trunk. Ann For Sci 68:985-992

Mansfield SD, Weineisen H (2007) Wood fiber quality and kraft pulping efficiencies of Trembling Aspen (Populus tremuloides Michx.) Clones. J Wood Chem and Tech 27:135-151

Nyakuengama JG, Evans R, Matheson C, Spencer D, Vinden P (1999) Wood quality and quantitative genetics of Pinus radiata $\mathrm{D}$. Don: fiber traits and wood density. Appita J 52:348-350

Olson JR, Jourdain CR, Rousseau RJ (1985) Selection for cellulose content, specific gravity and volume in young Populus deltoides clones. Can J For Res 15:393-396

Pitre FE, Cook JEK, Mackay JJ (2007) Short-term effects of nitrogen availability on wood formation and fibre properties in hybrid poplar. Tree Struc Func 21:249-259

Pliura A, Zhang SY, MacKay J, Bousquet J (2007) Genotypic variation in wood density and growth traits of poplar hybrids at four clonal trails. For Ecol Manag 238:92-106

Pot D, Guillaume C, Rozenberg P, Rodrigues JC, Jones GL, Pereira H, Hannrup B, Cahalan C, Plomion C (2002) Genetic control of pulp and timber properties in maritime pine (Pinus pinaster Ait.). Ann For Sci 59:563-575

$\mathrm{Pu}$ J, Song J, Yao C (2002) Variations in fiber forms of triploid clones of Populus tomentosa. J Beijing For Univ 24:62-66

Schimleck LR, Michell AJ, Raymond CA, Muneri A (1999) Estimation of basic density of Eucalyptus globulus using near-infrared spectroscopy. Can J For Res 29:194-202

Smith DM (1954) Maximum moisture content method for determining specific gravity of small wood samples. For Pro Lab Rep, No. 2014

Song W, Zhang ZY, Xu J (2000) Study on inheritance and variation of wood basic density of Populus tomentosa Carr. clones. Sci Silvae Sinicae 36:125-130

Stener L, Örjan H (2003) Genetic parameters of wood, fibre, stem quality and growth traits in a clone test with Betula pendula. Scand J Forest Res 18:103-110

Via BK, Stine M, Shupe TF, So CL, Groom L (2004) Genetic improvement of fiber length and coarseness based on paper product performance and material variability: a review. IAWA J 25:401-414

Wu F, Zhang PD, Pei JC, Kang XY (2011) Genetic variation of fiber properties of triploid Chinese white poplar planted in Beijing. J Northeast For Univ 39:4-7

Xing XT, Zhang ZY (2000) Genetic variation in wood density of triploid clones of Populus tomentosa. J Beijing For Univ 22:16-20

Yang S, Lu L, Ni Y (2006) Cloned poplar as a new fibre resource for the Chinese pulp and paper industry. Pulp Pap-Canada 107:34-37

Yu Q, Pulkkinen P, Rautio M, Haapanen M, Alen R, Stener LG, Beuker E, Tigerstedt PMA (2001) Genetic control of wood 
physiochemical properties, growth and phenology in hybrid aspen clones. Can J For Res 31:1348-1356

Zhang SY, Yu Q, Chauret G, Koubaa A (2003) Selection for both growth and wood properties in hybrid poplar clones. For Sci 49:901-908

Zhang PD, Wu F, Kang XY (2012) Genotypic variation in wood properties and growth traits of triploid hybrid clones of Populus tomentosa at three clonal trails. Tree Genet Genomes 8:1041-1050
Zhu ZT (2006) Genetic improvement of Populus tomentosa. Chinese Forestry Press, Beijing

Zhu ZT, Lin HB, Kang XY (1995) Studies on allotriploid breeding of Populus tomentosa B301 clones. Sci Silvae Sinicae 31:499-505

Zobel BJ, Jett JB (1995) Genetics of wood production. Springer, Berlin

Zobel BJ, van Buijtenen JP (1989) Wood variation, its causes and control. Springer, Berlin 